\title{
Assessment of Utilization of Integrated Child Development Services Scheme in Uttarakhand
}

Navuluri Kranthi Kumar Reddy ${ }^{1}$, Surekha Kishore ${ }^{2}$, Smita Sinha ${ }^{3}$, Ajeet Singh Bhadoria ${ }^{4}$, Yogesh Bahurupi ${ }^{5}$, Preeti Usha6, Abu Rehan? ${ }^{7}$ Bhavna Jain ${ }^{8}$

${ }^{1}$ Junior Resident, Department of Community and Family Medicine, All India Institute of Medical Sciences, Rishikesh, Uttarakhand; ${ }^{2} \mathrm{Head}$ and Professor, Department of Community and Family Medicine, All India Institute of Medical Sciences, Rishikesh, Uttarakhand ; ${ }^{3}$ Associate Professor, Department of Community and Family Medicine, All India Institute of Medical Sciences, Rishikesh, Uttarakhand $;{ }^{4}$ Assistant Professor, Department of Community and Family Medicine, All India Institute of Medical Sciences, Rishikesh, Uttarakhand; ${ }^{5}$ Assistant Professor, Department of Community and Family Medicine , All India Institute of Medical Sciences, Rishikesh, Uttarakhand; ${ }^{6}$ Junior Resident, Department of Community and Family Medicine, All India Institute of Medical Sciences, Rishikesh, Uttarakhand; ' 7 Junior Resident, Department of Community and Family Medicine, All India Institute of Medical Sciences, Rishikesh, Uttarakhand; ${ }^{8}$ Senior Resident, Department of Community and Family Medicine, All India Institute of Medical Sciences, Rishikesh, Uttarakhand.

\begin{tabular}{|c|c|c|c|c|c|c|c|}
\hline Abstract & Introduction & Methodology & Results & Conclusion & References & Citation & $\underline{\text { Tables } / \text { Figures }}$ \\
\hline
\end{tabular}

\section{Corresponding Author}

Navuluri Kranthi Kumar Reddy, Department of Community and Family Medicine, All India Institute of Medical Sciences, Rishikesh.

E Mail ID: kranthi1237@gmail.com

\section{Citation}

Reddy NKK, Kishore S, Sinha S, Bhadoria AS, Bahurupi Y, Usha P, Rehan A, Jain B. Assessment of Utilization of Integrated Child Development Services Scheme in Uttarakhand Indian J Comm Health. 2020;32(1):130-132.

Source of Funding: Nil Conflict of Interest: None declared

Article Cycle

\begin{tabular}{|c|}
\hline Received: $10 / 03 / 2020 ;$ Revision: $15 / 03 / 2020 ;$ Accepted: $18 / 03 / 2020 ;$ Published: 31/03/2020 \\
\hline This work is licensed under a Creative Commons Attribution 4.0 International License. \\
\hline
\end{tabular}

\section{Abstract}

Background: ICDS scheme has been playing its role effectively since 1975 when it was launched, but still there are some short comings which need to be addressed. Uttarakhand being one of the states with poor health indicators with respect to child and mother there is need to increase research on implementation of programs. Aims \& Objectives: The present study was conducted to see utilization of services provided under ICDS scheme in Uttarakhand. Material \& Methods: A cross sectional study was conducted in selected areas of Uttarakhand from October 2018 to June 2019. 505 households from 16 Anganwadi centers, from both urban and rural areas of Dehradun and Haridwar districts were included. Assessment of utilization of services was done by household interviews. Data was analyzed using SPSS V 23 software. Results: Availing supplementary nutrition services was the most utilized service $(94.5 \%)$ followed by health education services $(88.3 \%)$, health and referral services (83.2\%), preschool education services (76.7\%) and least utilized service was immunization service (69.3\%). Conclusion: Various factors independently affecting utilization of services were identified. Overall utilization of services is highest among pregnant women and least among adolescent girls and women of reproductive age group.

\section{Keywords}

ICDS; Anganwadi; Utilization; Supplementary Nutrition; Preschool Education

\section{Introduction}

"The children of today will make the India of tomorrow. The way we bring them up will determine the future of the country", said Jawaharlal Nehru, first prime minister of India. This statement tells us importance of upbringing and wellness in children for a better India in future. In order to address high infant mortality, malnourishment and poor learning outcomes at that time, Government of India had launched Integrated Child Development Services
(ICDS) scheme on October 2nd, 1975 on an experimental basis with support from UNICEF (1). This program is one of the largest, most prestigious and premier national human resource development programs by Government of India under Ministry of Women and Child development (2). In Uttarakhand at present among 13 districts there are 105 ICDS projects of which 8 are urban and 97 are rural. Under these projects out of a total 19614 Anganwadi and mini Anganwadi there are 1174 in urban and 18442 in rural 
areas respectively. For the functioning of these Anganwadi, 33055 Anganwadi workers/helpers are recruited. There is a need to explore factors to understand inability of ICDS to achieve expected results even after 40 years of implementation (3). A few published studies were available from Uttarakhand on ICDS (4-7). Uttarakhand being a state with poor health indicators especially with respect to child and mother health, there is need to augment research on implementation of programs that were focused on improving condition of children (8)

\section{Aims \& Objectives}

1. To assess utilization of services of ICDS by beneficiaries in Uttarakhand.

2. To assess factors affecting utilization of services of ICDS scheme.

\section{Material \& Methods}

Study design and the participants:

A Community based cross sectional study was done between October 2018 to May 2019 in urban and rural areas of Haridwar and Dehradun districts of Uttarakhand state, India. Households of beneficiaries of ICDS scheme were taken as unit of sampling. Beneficiaries included pregnant and lactating mothers, children (0-6 years) adolescent girls (10-19 years), women of reproductive age group (15-45 years) along with Anganwadi workers of the selected Anganwadi (9). A multistage random Cluster sampling technique was used to select Anganwadi centers. From thirteen districts in Uttarakhand, two districts Haridwar and Dehradun were randomly selected by simple random sampling using lottery technique. Four Anganwadi centers each from urban and rural areas of both districts were randomly selected by simple random sampling for conducting study. House to house interview was done in selected areas for obtaining data on utilization of services by households and factors affecting it. Household visits were done in catchment area of selected Anganwadi centers. Care was taken to include farthest household from the AWC

Utilization of services and factors affecting it were assessed by interview using a semi structured questionnaire comprising of items such as demographic profile of the house hold, services available for the beneficiaries under ICDS and satisfaction rating of each service utilized. Sample size was calculated considering prevalence of utilization of services to be $28.6 \%$ (10) and a design effect of 1.5. Sample was calculated as 483 households which was rounded off to 500. But 505 households were covered. Households of eligible beneficiaries from each selected Anganwadi was included in the study. Those immigrants to the Anganwadi catchment area who were not enrolled in Anganwadi center and participants who did not give consent to participate in the study were excluded. The data was entered into MS Excel and analyzed using SPSS version 23.0 for windows. Descriptive data was presented as frequencies, proportions and mean \pm standard deviations. Categorical variables were reported as proportions and continuous data as means \pm 2 standard deviation and median (IQR). To identify factors effecting utilization of services univariate analysis was done followed by binary logistic regression analysis. The categorical variables with multiple categories for which Cochran's criterion was not met and the continuous variables which were not in normal distribution were divided into two related categories. P-values less than 0.05 were considered to be statistically significant.

\section{Results}

Utilization of services under ICDS scheme in Uttarakhand varied for different services provided under it. (Table 1) shows at household level most utilized service was supplementary nutrition service (94.5\%) followed by nutrition and health education services (88.3\%), health and referral services (83.2\%), preschool education services (76.7\%) and least utilized service was immunization service (69.3\%). Most common reason for not sending children for preschool education at Anganwadi center was that people opt to send their children to private school (61.8\%). Most common reason for not taking supplementary nutrition was no felt need of taking supplementary nutrition (42.3\%). Regarding immunization, availing this service at sub center than Anganwadi center was found to be most common reason (91.7\%). Most common reason for not utilizing health and referral services under ICDS scheme was no felt need for these services (35.1\%). Overall utilization was highest among nursing mothers followed by antenatal mothers, children between 3-6 years age, children less than 3 years age, and least utilization was by adolescent girls and women of reproductive age group. Most common reason for not utilizing nutrition and health education services under ICDS scheme as reported by beneficiaries was that Anganwadi worker never give any advice (44.45\%). Satisfaction of households was with a median of 4 on a Likert scale of 0-5. Only factor that was significantly affecting preschool education activity was households having up to 3 total family members. Residing in urban area has an independent effect in utilization of supplementary nutrition services. Residing in rural area, belonging to Muslim religion, belonging to general caste, residing in $<100$ meters from Anganwadi center, households with $\leq 3$ family members, households with $\leq 2$ beneficiaries had significant independent effect on utilization of health and referral services under ICDS scheme. Residing in urban area, households with age of head of family $\leq 30$ years were affecting utilization of nutrition and health education services under ICDS scheme independently. (Table 2) depicts that on conducting a unique scoring for utilization of services by beneficiaries as percentage utilization score and it was highest among nursing mothers was $(85.0 \pm 23.9)$ followed 
by antenatal mother (79.2 \pm 38.9$)$. For rest of beneficiaries' median of utilization score of children of age between 3 to 6 years was (75), followed by Children $<3$ years $(66.7)$ and least by adolescents and female of reproductive age group (50). There was a significant difference between percentage utilization scores of antenatal mothers, children $<3$ years of age, and children of age group from 3 to 6 years among urban and rural area with more utilization scores in urban area.

\section{Conclusion}

The utilization of services under ICDS in Uttarakhand was varying for different services, with supplementary nutrition among highest utilized service and immunization among the least utilized service. The overall utilization was highest among the pregnant women and least among adolescent girls and women of reproductive age group. The overall satisfaction regarding the available services was with a median of 4 out of 5 on a liker scale for the services utilized under ICDS.

\section{Recommendation}

Even though ICDS scheme proved to be effective by improving condition of Children in our country there is still a felt need to upscale the scheme. Initiatives to involve community in various activities of ICDS scheme should be introduced by creating awareness on importance and impact of scheme. Awareness should be generated regarding the importance of supplementary nutrition and take-home ration. There is need to develop a new cadre of workers for various other activities of government like surveys, enrolment drives, election duties which will reduce burden on Anganwadi workers so that there is no difficulty in delivery of services under ICDS scheme.

\section{Limitation of the study}

Household was taken as sampling unit which made individual assessment of utilization difficult, however utilization scores for each type of beneficiary was calculated.

\section{Relevance of the study}

[Assessment of Utilization] | Reddy NKK et al

Despite of this functional scheme since last 40 years of its implementation, results and outcomes are not as expected. There is a need to explore factors to understand inability of ICDS to achieve expected results even after 40 years of implementation.

\section{Authors Contribution}

All authors have contributed equally.

\section{Acknowledgement}

The authors are grateful to the residents of selected households for their cooperation and participation in the study.

\section{References}

1. Rao N, Kaul V. India's integrated child development services scheme: challenges for scaling up. Child Care Health Dev. 2018 Jan 1;44(1):31-40.

2. Sachdev $Y$, Dasgupta J. Integrated child development services (ICDS) scheme. Med J Armed Forces India. 2001;57(2):139-43.

3. Jagadesh $\mathrm{H}$, Chandrika KB. Role of integrated child development scheme in India: A critical appraisal. Int J Humanit Soc Sci Res. 2017;3(10):18-21

4. Kaur GD, Aggarwal P, Kakkar R. Anthropometric profile of children attending anganwadi centers under integrated child development sevices (ICDS) scheme in doiwala block. Indian J Community Heal. 2015; 26:145-51.

5. Arya M, Sachan VK, Limbur R, Nautiyal P, Papnai G. Study on Knowledge of Anganwadi Workers about Integrated Child Development Services (ICDS) In Uttarkashi District of Uttarakhand. Anthropol. 2018;32(1-3):8-15.

6. Aggarwal P, Kandpal SD, Negi KS. Comparative study on practical application, acceptability and feasibility of different types of growth monitoring charts. Indian J Prev Soc Med. 2012;43(3):3328

7. Aggarwal P, Kakkar R. National Nutrition Strategy: The Needed Timely Modification to Make Integrated Child Development Scheme More Effective. Indian J Pediatr. 2019;86(7):628-32.

8. Indian Institute for Population Sciences. National Family Health Survey 4: State Fact Sheet, Uttarakhand. 2016.

9. Gangbar J, Rajan P, Gayithri K. Integrated child development services in India- A Sub-Ntional Review. Inst Soc Econ Chang. 2014;1(4):1-20.

10. Ministry of woman and child development Governement of India. Rapid Survey on Children. 2014.

\section{Tables}

\begin{tabular}{|c|c|c|}
\hline S. No & Service & Utilization \\
\hline 1 & Preschool education $(\mathrm{N}=146)$ & $112(76.7 \%)$ \\
\hline 2 & Supplementary nutrition $(\mathrm{N}=471)$ & $441(94.5 \%)$ \\
\hline 3 & Immunization ( $\mathrm{N}=473$ ) & $328(69.3 \%)$ \\
\hline 4 & Health and referral $(\mathrm{N}=505)$ & $420(83.2 \%)$ \\
\hline 5 & Nutrition and health education ( $\mathrm{N}=505)$ & $446(88.3 \%)$ \\
\hline
\end{tabular}

TABLE 2 PERCENT UTILIZATION OF ICDS SERVICES BY THE BENEFICIARIES

\begin{tabular}{|l|l|l|}
\hline S. No & Type of beneficiary & \% Utilization (Mean $\pm 2 S D)$ \\
\hline 1 & Pregnant women $(\mathrm{N}=228)$ & $79.2 \pm 38.9$ \\
\hline 2 & Lactating mothers $(\mathrm{N}=137)$ & $85 . \pm 23.9$ \\
\hline 3 & Children below 3 years $(\mathrm{N}=277)$ & $66.7^{*}(66.7-66.7)$ \\
\hline 4 & Children of age between 3 to 6 years $(\mathrm{N}=153)$ & $75^{*}(50-100)$ \\
\hline 5 & Adolescent girls and women of reproductive age group $(19-45$ years $)(\mathrm{N}=204)$ & $50 *(0-75)$ \\
\hline
\end{tabular}

*Median (IQR) 